\title{
QUILOMBO, IDENTIDADE E EDUCAÇÃO ESCOLAR: O ENSINO DE HISTÓRIA NA ESCOLA DAVID MIRANDA EM SANTANA-AMAPÁ
}

\author{
QUILOMBO, IDENTITY AND SCHOOL EDUCATION: THE TEACHING OF \\ HISTORY IN SCHOOL DAVID MIRANDA IN SANTANA-AMAPÁ
}

\author{
Elivaldo Serrão Custódio ${ }^{1}$ \\ Eugénia da Luz Silva Foster² \\ Silvaney Rubens Alves de Souza ${ }^{3}$
}

\begin{abstract}
RESUMO: O presente artigo objetiva discutir sobre quilombo, identidade $\mathrm{e}$ educação escolar: o ensino de história na escola David Miranda localizada no município de Santana, estado do Amapá. Trata-se de um estudo exploratório de abordagem qualitativa que utilizou da pesquisa bibliográfica, a análise documental, a observação direta e a entrevista como forma de investigação. O trabalho analisou um projeto pedagógico da referida escola chamado "Identidade Cultural", cuja essência representa uma interessante experiência de ação pedagógica, onde saberes da comunidade local em conjunto com uma sensibilidade dos educadores, produziu um diálogo entre o passado e o presente que contribuiu para fortalecer a identidade de uma comunidade que anseia pelos seus direitos e busca resguardar a sua propriedade e sua memória cultural. Os resultados da pesquisa revelam que a experiência ocorrida na escola local demonstra que ainda há um longo caminho a ser trilhado na busca de uma educação quilombola efetiva no estado do Amapá, mas os agentes sociais que fazem a escola, estão se esforçando na árdua tarefa de construir uma educação adequada aos novos anseios da comunidade local.
\end{abstract}

\footnotetext{
${ }^{1}$ Pós-Doutor em Educação pela Universidade Federal do Amapá (UNIFAP). Doutor em Teologia pela Faculdades EST, em São Leopoldo/RS. Pedagogo, Matemático e Teólogo. Vicelíder do Grupo de Pesquisa Educação, Interculturalidade e Relações Étnico-Raciais cadastrado no CNPq. Atualmente é professor permanente no Mestrado em Educação (PPGED/UNIFAP) e professor do Curso de Pedagogia da Faculdade Madre Tereza em Santana/Amapá/Brasil. Email: elivaldo.pa@hotmail.com. ORCID <http://orcid.org/0000-0002-2947-5347>

2 Professora Associada IV da Universidade Federal do Amapá (UNIFAP) nos cursos de Graduação em Pedagogia, Mestrado em Educação (PPGED/UNIFAP) e Mestrado em Desenvolvimento Regional (MDR/UNIFAP). Doutora em Educação pela Universidade Federal de Fluminense (UFF). Pós-Doutora em Educação pela Universidade Estadual do Rio de Janeiro (UERJ). Líder do Grupo de Pesquisa Educação, Interculturalidade e Relações ÉtnicoRaciais, cadastrado no CNPq. E-mail: eugenia.luz@hotmail.com. ORCID <http://orcid.org/0000-0002-0807-0789>

3 Mestrando do Programa de Pós-Graduação em Desenvolvimento Regional da Universidade Federal do Amapá (MDR/UNIFAP). Especialista em História e Historiografia da Amazônia pela Universidade Federal do Amapá. Professor de História da rede pública estadual de ensino do estado do Amapá. E-mail: silvaney.rubens@gmail.com. ORCID <http://orcid.org/0000-00023684-4120>
}

História \& Ensino, Londrina, v. 25, n. 1, p. 253-277, jan./jun. 2019 
Palavras-chave: Quilombo. Identidade. Educação escolar. Ensino de história.

Amapá.

\begin{abstract}
This article aims to discuss quilombo, identity and school education: the teaching of history at the David Miranda school located in the municipality of Santana, Amapá state. It is an exploratory study of a qualitative approach that used bibliographic research, documentary analysis, direct observation and interview as a form of investigation. The work analyzed a pedagogical project of this school called "Cultural Identity", whose essence represents an interesting experience of pedagogical action, where local community knowledge together with a sensitivity of the educators, produced a dialogue between the past and the present that contributed to strengthen the identity of a community that longs for its rights and seeks to safeguard its property and its cultural memory. The results of the research reveal that the experience of the local school demonstrates that there is still a long way to go in the quest for an effective quilombola education in the state of Amapá, but the social agents who make the school are struggling in the arduous task of building an education appropriate to the new yearnings of the local community.
\end{abstract}

Keywords: Quilombo. Identity. Schooling. History teaching. Amapá

\title{
Introdução
}

A crescente demanda por uma educação de qualidade que atenda diversos interesses de grupos e agentes sociais, nos instiga a refletir sobre - reconhecimento da educação quilombola como uma importante modalidade de ensino em destaque, sendo esta fruto de uma intensa luta dos grupos remanescentes de quilombos, que reconhecem na educação destinada as suas crianças uma problemática a ser enfrentada, cujo fim consiste na valorização da identidade dos grupos remanescentes de quilombolas na contemporaneidade.

Tomamos como ponto de partida o relatório final da Conferência Nacional de Educação (CONAE) de 2012, onde podemos observar que as falas dos representantes das comunidades remanescentes de quilombos presentes, através de sua representação nacional Coordenação Nacional de Articulação das Comunidades Negras Rurais Quilombolas (CONAQ), fez-se ouvir através de suas reivindicações, que dentre outras coisas exigiram a garantia de elaboração de uma legislação específica para a educação quilombola, com a participação do movimento negro quilombola, 
assegurando o direito à preservação de suas manifestações culturais e à sustentabilidade de seu território tradicional. Soma-se a essas reivindicações, uma maior atenção à educação em suas comunidades, como: a criação de escolas, critérios nas escolhas dos professores para as comunidades e, principalmente, qualificação para os professores que atuam em "escolas quilombolas".

No bojo dessa discussão é que surge a questão a respeito da identidade desses grupos. Será que nas comunidades de remanescentes de quilombos onde existem escolas, há uma maior percepção de identidade de grupo? Será que as escolas, como um espaço de conhecimento normativo e científico, têm interagido com o saber e as vivências da comunidade quilombola em que está situada? E o ensino de história, tem contribuído para a ressignificação dos valores sociais e culturais coletivos construídos historicamente pela comunidade?

O presente texto é um estudo exploratório de abordagem qualitativa que utilizou da pesquisa bibliográfica, a análise documental, a observação direta e a entrevista como forma de investigação. Buscando responder as questões ora mencionadas a partir de uma análise sobre alguns aspectos relacionados à educação escolar e o ensino de história, vamos nos restringir à comunidade de remanescentes de quilombolas de São José do Matapi do Porto do Céu, no estado do Amapá, caracterizada como ribeirinha pela sua localização à margem do rio Matapi, localizada entre o municípios de Macapá e Santana, cujo processo de auto reconhecimento e titulação está em andamento nos órgãos competentes como no Instituto Nacional de Colonização e Reforma Agrária (INCRA) e/ou Secretaria Extraordinária de Políticas para os Povos Afrodescendentes (SEAFRO). No seu território existe a escola Estadual David Miranda dos Santos.

Para compreender o ensino da história, vamos analisar alguns produtos pedagógicos resultantes do projeto intitulado "Identidade Cultural $^{\prime 4}$, que mesmo com caráter transdisciplinar, serviu de base para

\footnotetext{
${ }^{4}$ O projeto "Identidade Cultural" foi um trabalho desenvolvido a partir do ano de 2007 pelo Núcleo de Educação Étnico-Racial (NEER) da Secretaria de Estado da Educação do Amapá
} 
coletar informações importantes sobre a metodologia do ensino de história, além de possibilitar uma visão por amostragem, da educação no referido território de remanescentes quilombolas.

A delimitação temporal do projeto que compreende aos anos de 2011 a 2015, nos ajuda a contextualizá-lo frente às transformações nas legislações, seja através de resoluções, pareceres e/ou diretrizes, nacionais ou estaduais, que ocorreram ao longo do período. Contudo, procuramos nos deter nos aspectos pertinentes a percepção dos profissionais da escola e líderes da comunidade selecionados para uma entrevista, observando o "Projeto identidade cultural" e a principal lei que media as discussões sobre africanidade na educação brasileira, a Lei n 10.639/2003, caracterizada pela obrigatoriedade do ensino da história e Cultura da África e dos afrodescendentes.

Neste artigo, utilizamos a denominação "remanescentes de quilombo" para os afrodescendentes que compartilham experiências históricas além do uso coletivo das terras, haja vista, que "a expressão "remanescente das comunidades de quilombos", que emerge na Assembleia Constituinte de 1988, é tributário não somente dos pleitos por títulos fundiários, mas de uma discussão mais ampla travada nos movimentos negros e entre parlamentares envolvidos com a luta antirracista (LEITE, 2000, p. 339).

Acreditamos que este trabalho contribuirá para a compreensão da emergência de uma educação, principalmente o ensino de história, apropriada no território remanescente quilombola, no estado do Amapá, cujo currículo seja adequado às Diretrizes Nacionais para a educação escolar quilombola, contribuindo para a quebra de um paradigma educacional eurocêntrico universalizante e alheio às especificidades das comunidades em questão.

Para tanto, o artigo tem com corpo estrutural os seguintes eixos: no primeiro tópico, apresentamos conceitos preliminares sobre Quilombo: 
histórias de resistência. No segundo tópico abordamos sobre o ensino da história e a comunidade de remanescente quilombola. Por último, analisamos o projeto pedagógico desenvolvido na escola intitulado "Identidade Cultural", Zumbi e o quilombo, trazendo as considerações finais.

\section{Quilombo: histórias de resistência}

O processo de interação dos vários grupos étnicos na região amazônica não pode ser entendido como um fenômeno harmônico, mas como resultado de um sistema econômico denominado de "sistema colonial", onde toda a base da economia estava sustentada pela força de trabalho escravo, que por sua vez, fomentava o tráfico constante de "almas", que auferiam lucro a um seleto grupo que detinha a hegemonia política, econômica e cultural da região.

Este processo possibilitou um contato com diferentes grupos de africanos transportados de diversas regiões da África, que aqui se encontraram com os demais grupos étnicos, em uma condição de harmonia, segundo um discurso dominante, onde a solidariedade residia na condição de cativo e/ou de submissão. Portanto, aqui também encontraram o elemento indígena "reduzido à mesma condição de escravo ou servo de gleba, numa convivência mais ou menos promiscua com soldados e colonos oriundos das classes populares do velho mundo" (SALLES, 1989, p. 80).

Salles (1989) nos apresenta um olhar um tanto simplista e até ofensivo ao descrever a experiência histórica dos africanos como "uma convivência mais ou menos promiscua" negligenciando a violência no qual os indígenas e trabalhadores africanos foram submetidos na condição de escravos.

Esse processo de interação, mais as disputas do jogo geopolítico estabelecido na região Amazônica entre as grandes nações europeias, possibilitaram aos negros uma maior mobilidade espacial e de resistência, como nos deixa entender Flávio dos Santos Gomes: 
Devido as suas situações geopolíticas, as capitanias do GrãoPará e do Rio Negro, na Amazônia, divisavam com territórios coloniais sob domínios espanhol, inglês, holandês e francês. O cenário principal para esses 'bumerangues' era a região de Macapá, na capitania do Grão-Pará, que limitavam-se com a Guiana Francesa. Havia ali uma constante motivação de fugas de escravos e formação de quilombos desde o primeiro quartel dos setecentos (GOMES, 1996, p. 135-136).

Mobilidade e resistência que, por sua vez, permitiram a formação de quilombos no espaço do território amazônico, já que, o "destino" natural do negro fugido era o mocambo (SALLES, 1988).

Voltando a Gomes (1996), que considera a fuga de escravos e a formação de quilombos um problema crônico a ser enfrentado pelas autoridades imperiais, observamos a grande movimentação ocasionada pelo que o autor convencionou chamar de "bumerangue quilombola", o que seria a constante troca de informações, produtos e experiências, e por que não falar, também, de solidariedades, entre essas populações "fugidas" nessa imensa região de fronteiras localizada na Amazônia:

Esses quilombolas andavam armados, produziam roupas tingidas com vegetais da floresta, caçavam, 'salgavam' carne para comerciar e 'faziam tijolos para os franceses fazerem uma fortaleza'. Neste contexto, naquelas regiões da Amazônia colonial, negros - fossem escravos ou livres, fugidos - criaram um espaço para contatos e cooperação. Com experiências diferenciadas e sonhando com a liberdade, promoviam não só comércio clandestino, mas fundamentalmente um campo de circulação de experiências [...] transformaram-se, assim, em 'bumerangues quilombolas (GOMES, 1996, p. 139).

Deste modo, Gomes (1996) nos ajuda a pensar o quilombo, não como um lugar isolado do mundo a sua volta, mas como um lugar onde havia um movimento de ida e volta, seja de informações e/ou produtos, transformando o conjunto de seus contemporâneos em catalisadores de informações, e por que não dizer também, um espaço crível de intensa fomentação de ideias, cujas mesmas circulavam pelos portos de várias regiões do mundo, dadas as devidas proporções, num constante processo de troca de produtos e mercadorias entre metrópoles e colônias. 
Ainda sobre a presença da população negra na Amazônia, Vicente Salles, nos mostra que neste processo de ocupação, nem tudo foi tão simples, pois haviam outros, que se enquadravam na mesma condição social, não como escravos, mas como indivíduos de classe inferior, como era o caso dos índios, possibilitando que os "contatos inte rétnicos se processaram intensamente, isentos do mais rudimentar preconceito racial, fundindo num todo os três estoques fundamentais: o branco, o índio e o negro" (SALLES, 1988, p. 69).

Por esse motivo, temos a constatação que o negro não se conservou "puro", mesmo por que não sofreu pressões segregadoras, misturando-se facilmente à massa da população (SALLES, 1988). Acreditamos que não tão "facilmente", como afirma Salles (1988) e não sem tais "pressões", mas de qualquer modo, participou sim desse processo intercultural, o que justificaria a grande pluralidade de manifestações culturais genuinamente brasileira e amazônica, fruto de uma intensa troca material e imaterial, resultando em novos elementos culturais brasileiro, amazônicas e amapaenses.

Portanto, mais do que entender a presença negra na Amazônia, é preciso compreender que os afro-brasileiros, para além de serem enquadrados dentro de uma lógica coisificada dentro do sistema colonial, esses indivíduos foram capazes de se adaptar a um conjunto de situações e, sempre que possível, desenvolveram suas próprias lógicas de resistência, seja na criação de quilombos, seja na participação em conflitos armados contra a opressão da elite dominante como na Cabanagem ${ }^{5}$, seja através de violência física ou quebra de equipamentos e até mesmo na reivindicação de melhores condições de trabalho (LARA, 1988).

Para pensar a educação quilombola é necessário também nos remeter aos conceitos históricos que temos acerca do território remanescente de quilombo que, segundo Ilka Boa Ventura Leite, sofreu várias modificações ao longo da história e:

\footnotetext{
${ }^{5}$ A Cabanagem foi uma revolta popular extremamente violenta, ocorrida de 1835 a 1840 , na província do Grão-Pará.
} 
O quilombo constitui questão relevante desde os primeiros focos de resistência dos africanos ao escravismo colonial, reaparece com a Frente Negra Brasileira (1930/40) e retorna à cena política nos anos 70 , durante a redemocratização do país. Trata-se, portanto, de uma questão persistente, tendo na atualidade importante dimensão na luta dos afrodescendentes (LEITE, 2000, p. 333).

Assim, o quilombo, mas do que uma nomenclatura ressemantizada, tornou-se uma importante identidade coletiva, construída no processo histórico pelos afrodescendentes, visando a garantia direitos coletivos outrora negados, seja a titulação definitiva do seu território, seja uma educação escolar que reconheça e garanta a sua reprodução sócio histórica no conjunto de uma sociedade multicultural como a brasileira.

E se tornaram sujeitos protagonistas de uma presença marcante, não só na história do Grão-Pará e Maranhão, do período colonial, mas em todo o Brasil contemporâneo, como indivíduos capazes de superar as suas condições de exploração na busca de alternativas, a partir das adversidades propiciadas seja realidade do sistema colonial, seja na contemporaneidade, por melhorias no seu modo de vida e reprodução de sua cultura.

Portanto, o estado Amapá pela sua construção histórica, onde "os trabalhadores africanos compuseram, ao lado dos ameríndios e colonos portugueses de poucas posses as multiplicidades sociais da vila de São José de Macapá" (LUNA, 2011, p. 74), não foge à realidade brasileira e, por isso, a prevalência de vários territórios étnicos e tradicionais, sejam eles indígenas ou quilombolas e alguns com a escolas instaladas.

A escola Estadual David Miranda dos Santos ${ }^{6}$ tem seu ato de fundação oficial datado de fevereiro de 1993, com a autorização de funcionamento da $5^{a}$ a $8^{a}$ série, e endereço descrito na Comunidade Quilombola de São José de Matapi, no 156, localidade Porto do Céu.

A escola oferta a modalidade de ensino fundamental, do primeiro e segundo seguimento, ou seja do $1^{\circ}$ ao $9^{\circ}$ ano, e atende uma clientela de crianças remanescentes de quilombo da própria comunidade, São José do

\footnotetext{
${ }^{6}$ A escola dispõe apenas de 05 salas de aulas e atende em média 240 alunos, sua construção é em madeira e está precisando de uma reforma, ainda sim no ano de 2015 alcançou a media 4,0 no IDEB, nota maior que a média do estado que foi 3,6 .
} 
Matapi e de outras no entorno: São Tomé do alto Pirativa, Cinco Chagas, São João do Matapi e demais localidade ribeirinha do rio Matapi, mas não só, devido ao crescimento das comunidades litigantes que a cercam (invasão), há um grande número de alunos "posseiros", cuja presença é recente, além do alunos do distrito do coração, já que a escola, curiosamente é a única da região a oferecer o segundo seguimento em modalidade regular 7 .

Acreditamos que essa escola é uma pequena amostra para a compreensão da percepção da educação escolar destinada aos remanescentes quilombolas no estado do Amapá, dada as suas características únicas, haja vista que buscou através do projeto "Identidade Cultural" apresentar uma alternativa para a educação da comunidade escolar atendida, associada aos anseios dos líderes comunitários e contemporâneos às novas legislações dos órgãos competentes.

\section{O ensino da história e a comunidade de remanescente quilombola}

O ponto de partida para a compreensão política e institucional da importância da comunidades tradicionais, bem como dos diversos grupos que compõe a sociedade brasileira, se encontra na Constituição Federal de 1988 que expressa que o reconhecimento institucional do Estado Brasileiro aos direitos de diversos grupos não só ao território, mas principalmente ao uso dos recursos naturais, a partir do reconhecimento da importância dos diversos grupos sociais e étnicos e suas identidades coletivas para a sociedade brasileira. Assim, as comunidades tradicionais de remanescentes de quilombolas ganham reconhecimento e importância no âmbito institucional, já que a existência e reconhecimento dessas comunidades advém de um processo histórico anterior a Carta Magna de 1988, principalmente no contexto da região amazônica.

\footnotetext{
7 Existe a oferta em comunidades próximas do segundo segmento da educação básica, mas de forma 'modular", onde as matérias são concentradas e professores se revezam no durante o período letivo.
} 
A Constituição Cidadã de 1988, reconheceu a importância cultural e identitária como patrimônio cultural de interesse da União, estados e municípios e como tal, devem ser preservados garantindo a sua manutenção e integridade, uma vez que os territórios integram a formação da identidade nacional.

É nesse contexto, que a Lei $n^{\circ} 10.639 / 2003$ e $11.645 / 2008$, que altera a Lei de Diretrizes e Base da Educação Nacional (LDB) $\mathrm{n}^{\circ}$ 9.394/1998, vem contribuir para o reconhecimento e preservação da história e cultura desses territórios, instituindo a obrigatoriedade do ensino da história da África e cultura Afro-brasileira e indígena, no currículo escolar de todo o Brasil.

E no caso específico desses territórios étnicos existe um diferencial; elas próprias são a fonte histórica e a principal representação cultural afrobrasileira na contemporaneidade. Portanto, suas tradições precisam sobreviver pragmaticamente, assim como a memória coletiva para garantir a preservação desses grupos enquanto experiências culturais e históricas únicas.

No Amapá há uma grande prevalência de grupos remanescentes de quilombos, alguns deles, até integrados a áreas urbanas e com suas terras certificadas e tituladas: como é o caso do Curiaú, Mel da Pedreira e Conceição do Macacoari. Já outras comunidades, buscam o seu reconhecimento histórico e cultural, onde o processo de reconhecimento e titulação, junto INCRA ainda está em andamento.

De acordo com levantamento da Fundação Palmares e da SEAFRO, no Amapá foram identificadas 138 comunidades de remanescentes de quilombolas, sendo que desse universo, apenas 40 conseguiram a sua certidão de auto reconhecimento emitido pela Fundação Cultural Palmares, conforme o quadro geral de remanescentes de quilombos expedido pelo INCRA $^{8}$ e, apenas as Comunidades citadas acima, possuem o título definitivo de suas terras, delimitando a área da comunidade quilombola.

\footnotetext{
${ }^{8}$ Ver http://www.palmares.gov.br/wp-content/uploads/2016/06/QUADRO-RESUMO.pdf.
} 
Segundo Fonseca (2003), a universalização da educação no Brasil e no mundo tornou visível uma melhor compreensão do currículo e sua construção ideológica, principalmente no contexto da seleção dos conhecimentos do que se ensina e do que se aprende para uma sociedade contemporânea, que tem na educação mais do que um direito, mais uma necessidade de transmissão, manutenção e perpetuação de um conhecimento caracterizado como importante para o conjunto da sociedade, e vai mais além ao afirmar:

O texto dos parâmetros curriculares nacionais para o ensino fundamental em história, lançado oficialmente pelo ministério da Educação em 1997, tenta dar uma resposta sobre o que da nossa cultura, da nossa memória é mais adequado para transmitir as novas gerações que frequentam as escolas nas diferentes realidades socioculturais do Brasil (FONSECA, 2003, p. 32).

Desta forma, não há dúvida de que a história enquanto disciplina entra nesse contexto e se amplia enquanto possibilidade de diálogos e de disputas ideológica inerentes às sociedades contemporâneas, trazendo para o seu seio, uma profunda discussão sobre os seus saberes validos enquanto conhecimentos a serem transmitidos ao conjunto de uma sociedade diversificada em sua multiplicidade cultural.

Portanto, um dos marcos iniciais desse processo de mudança está inserido nos Parâmetros Curriculares Nacionais ( $P C N$ 's), para o ensino de história na educação básica, que trouxe consigo novos referenciais, conceitos e propostas metodológicas para a disciplina história, buscando uma adequação às novas realidades políticas e social de um país em transformação, findado o longo período obscuro de um governo militar. ${ }^{9}$

Os Parâmetros Curriculares Nacionais surgem de uma demanda educacional onde debates e reflexões resultaram na construção de um

\footnotetext{
${ }^{9}$ Em relação ao Amapá, embora o Estado atualmente possua suas próprias diretrizes curriculares estadual - última versão oficial datada de 2018 -, segundo Custódio (2019, p. 12), somente a partir de 2003 iniciaram-se as "[...] reivindicações para a atualização da política educacional $[\ldots]$ ". No entanto, essa "atualização está sendo feita com muita lentidão, haja vista que as estruturas tradicionais do estado não modificaram. Mesmo com as mudanças que ocorreram na estrutura organizacional da SEED, muitas situações continuam no mesmo lugar literalmente".
} 
documento referencial de caráter normativo e consultivo que auxilie na fundamentação das aulas, em nível nacional no ensino básico.

E, na área de Ensino de História, se aprofundam as discussões no tocante à utilização do tempo, da cronologia oficial (o estabelecimento de linha cronológica) e da ação individual e coletiva na construção da história humana, onde "de modo geral, pode-se dizer que os fatos históricos remetem para as ações realizadas por indivíduos e pelas coletividades, envolvendo eventos políticos, sociais, econômicos e culturais" (BRASIL, 1997b, p. 39).

Deste modo, o maior avanço no contexto do currículo e do processo de ensino aprendizagem, e consequentemente na seleção do que se ensina e se aprende, chega com as novas alterações que inclui no contexto do ensino a educação para as relações étnico-raciais. E, segundo Petronilha Silva:

As diretrizes curriculares nacionais para o ensino de história e cultura Afro-Brasileira e Africana, nos termos do CNE/CP $3 / 2004$ e da respectiva resolução $\mathrm{CNE} / \mathrm{CP} 1 / 2004$, estabelecem a educação para as relações étnico-raciais, como um núcleo dos projetos pedagógicos das instituições de ensino de diferentes graus e como um dos focos dos procedimentos e instrumentos utilizados para avaliação e supervisão. Dizendo de outro modo, ao se avalizar a qualidade das condições de ofertas e educação por escolas e universidades, tem-se, entre outros quesitos a observar, a realização de atividades intencionalmente dirigidas à educação das relações étnico-raciais (SILVA, 2007, p. 490).

Portanto, a educação das relações étnico-raciais entra no contexto da educação brasileira como elementos obrigatórios para as instituições de ensino, na observação de uma educação de qualidade, e nos aponta uma mudança significativa no contexto da educação, no que diz respeito não só a flexibilização do olhar no processo de ensino-aprendizagem, mas dos seus atores, suas histórias e o conjuntos de seus saberes tradicionais.

Deste modo, o ensino escolar em território quilombola deve conter as seguintes especificidades, segundo a Resolução Nacional: "O direito à igualdade, a liberdade, diversidade e pluralidade; a proteção das 
manifestações da cultura afro-brasileira"; além do "o conhecimento dos processos históricos de luta pela regularização dos territórios tradicionais dos povos quilombolas" (BRASIL, 2012).

Destacamos os itens que trazem para o contexto da educação e do currículo escolar itens inerentes à história de luta das comunidades de remanescentes pelo seu reconhecimento e valorização de seus saberes, se constituindo uma verdadeira ruptura, no que concerne o escopo de conhecimentos válidos para uma sociedade que tem a Europa como elementos valorativos importantes no processo civilizatório.

Nesse sentido, palavras como: manifestações afro-brasileiras, reconhecimento dos quilombolas, reconhecimento de suas lutas e direito ao etnodesenvolvimento, passam a fazer parte no contexto de seleção de saberes e conhecimentos validos, e o território, um importante conceito a ser trabalhado de forma unitária, comunal e imprescindível para a manutenção do conjunto de indivíduos que o ocupam historicamente, o que caracteriza ao nosso ver, uma ruptura de paradigma que se processa no currículo, conciliando o "formal e o real" em um único, viável e necessário para o contexto da especificidade dos remanescentes de quilombola.

Mas ao inquirir uma Professora de história sobre o processo de escolha do livro didático, da escola David Miranda, obtive a seguinte resposta: "o livro não foi escolhido, o livro que chega e o que a gente utiliza $^{10 ",}$ o que nos remete a várias problemáticas: A escola por ser caracterizada como quilombola e estar distante do centro urbano, mesmo tendo um número de alunos significativo ${ }^{11}$, nos parece ser desprestigiada no processo relevante da escolha dessa importante ferramenta didática pelos gestores, pois informa que houve a escolha em sua escola, mas veio a segunda opção.

Portanto, mesmo sendo necessário um estudo aprofundado sobre os vários aspectos que envolvem a Política Nacional do livro didático e os profissionais que os escolhem, além das condições estruturais de tais escolas, já que para Piedade Videira, "estas condições materiais e de

\footnotetext{
10 Resposta obtida em entrevista.

11 Escola David Miranda - 214 alunos (EDUCACENSO, 2011).
} 
formação de professores são indispensáveis para uma educação de qualidade para todos, assim como o é o reconhecimento e valorização da história, cultura e identidades dos descendentes de africanos" (VIDEIRA, 2009 , p. 250). Constatamos com base nesta afirmação que ao livro didático, não se tem observado seu real valor e importância quando se trata do processo de ensino e a aprendizagem local, e isso se tornar mais evidente quando questionamos: como trabalhar as especificidades de construção identitária nessas escolas quilombolas, onde sequer o direito de escolha do livro didático foi exercido plenamente?

A resposta nos surpreende, na medida em que, "as professoras ${ }^{12 "}$ de história, inquiridas, são conhecedoras da Lei n 10.639/2003 e utilizamse de materiais variados para compor a sua gama de ferramentas pedagógicas, para além do livro didático, tais como: vídeos institucionais sobre identidades quilombolas, materiais editoriais nacionais de fortalecimento institucional de comunidades quilombolas, além de projetos pedagógicos que interagem com a comunidade, em que a escola está situada, corroborando deste modo, com a ideia de que os quilombos "construíram uma história que não é apenas de fuga da escravidão, mas do desejo pela liberdade; é uma história de vários capítulos, ocorridas em vários lugares e de diferentes modos" (NUNES, 2006, p. 145).

Sendo assim, ao que parece o livro didático não contribui de forma relevante para o conhecimento e ressignificação dos valores históricos construídos, historicamente pela comunidade quilombola, já que o fazer pedagógico das professoras, em questão, "é uma difícil e árdua tarefa de esforço individual de pesquisa e investimento em conhecimento sobre o tema ${ }^{13 \prime \prime}$, para além do livro didático.

Portanto, é evidente que o esforço de iniciativas isoladas e individuais, por dentro da estrutura institucional de educação, é uma condição sine qua non para um novo fazer pedagógico que, segundo Nunes "passa pelo momento de reflexão e da ação, não dicotomizados, formadores

\footnotetext{
${ }^{12}$ As duas professoras são as únicas que trabalham com a disciplina história em suas escolas, estando a mais de três anos exercendo suas atividades, nas escolas citadas, ambas são pós-graduadas.

${ }^{13}$ Relato obtido em diálogos com os participantes da pesquisa.
} 
de uma unidade que se chama práxis" (NUNES, 2006, p. 140). Enquanto que, a nosso ver, o correto seria a construção de uma ação coletiva, planejada e respaldada por políticas públicas efetivas que torne prioridade essa demanda especifica da educação, que tanto necessitam os remanescentes de quilombos, pelo seu passado histórico de lutas pela sobrevivência e como demanda as resoluções nacional e estadual.

Com base nesse breve relato, podemos concluir que há um longo caminho a percorrer para que as comunidades quilombolas tenham uma escola que, realmente esteja a serviço da comunidade, no sentido de garantir, para além do conhecimento cientifico formal, cuja concretização é evidenciada no "currículo manifesto", mas também, a preservação de sua cultura e o resgate de sua identidade. Ressaltamos que são validas todas e quaisquer iniciativas individuais que visem garantir a ressignificação dos conceitos valorativos que definem o grupo em questão.

A disciplina história adentra nesse processo como uma ferramenta poderosa e fundamental, sem sombra de dúvida, mas não pode trilhar sozinha este caminho, sendo necessária uma ampla discussão sobre o currículo manifesto, inclusive com a participação dos representantes dessas comunidades, que a muito lutam por uma educação de qualidade. Enquanto que a lei 10.639/2003 assume um importante papel de política pública na garantia de uma reparação história, corroborando com a visibilidade, contextualização e desconstrução de conceitos cristalizados dessas comunidades no período histórico pós-escravatura.

E o quilombo deve ser compreendido como um espaço pleno de direito, conquistas e história, pois segundo Milton Santos:

O espaço deve ser considerado como uma totalidade, a exemplo da própria sociedade que Ihe dá vida [...] o espaço deve ser considerado como um conjunto de funções e formas que se apresentam por processos do passado e do presente [...] o espaço se define como um conjunto de formas representativas de relações sociais do passado e do presente e por uma estrutura representada por relações sociais que se manifestam através de processos e funções (SANTOS, 2002, p. 122). 
Cujo conceito de espaço, ao nosso ver, traz para a contemporaneidade uma representação adequada para se pensar o conjunto de elementos que representam os remanescentes quilombolas e seus saberes, no contexto de um espaço geográfico, constituído pela sua história de luta, e preservada pelas suas manifestações culturais, já que o mesmo "é o resultado de uma práxis coletiva que reproduz as relações sociais, [...] o espaço evolui pelo movimento da sociedade total" (SANTOS, 2002, p. 171).

Deste modo, a Escola Estadual David Miranda se apresenta como parte integrante da comunidade, de suas memórias e de suas expectativas quanto ao futuro, sendo este um terreno incerto, mas esperançoso, como o é a tão sonhada e esperada titulação definitiva do território da comunidade de remanescente quilombola São José do Matapí do Porto do Céu.

\section{O Projeto "Identidade Cultural", Zumbi e o quilombo}

Para efeito de análise do ensino da história, integrado aos PCN's e às novas Diretrizes Curriculares Nacionais para a Educação Escolar Quilombola, vamos discorrer sobre a experiência do projeto interdisciplinar chamado "Identidade Cultural", cujo projeto teve início no ano de 2007, e representa o caráter inovador de uma educação integrada a comunidade e seus aspectos sociais e culturais, no que concerne a construção de uma identidade quilombola e a ressignificação de valores e conceitos históricos para a comunidade e o seu entorno.

Acreditamos que o "Identidade Cultural" se apresenta como uma proposta inovadora e contextualizada aos novos conceitos basilares de uma sociedade em transformação, como a brasileira com um objetivo claro descrito abaixo:

Valorização da diversidade étnico racial existente na sociedade brasileira, através do resgate das manifestações culturais, buscou-se (re) conhecer a contribuição de cada grupo étnico na construção da sociedade brasileira e, mais especificamente amapaense, resgatando valores identitários, inerentes aos educandos, a partir do seu pertencimento 
histórico e cultural. Buscou-se também, apresentar praticas pedagógicas inovadoras, inseridos no contexto da legislação federal (10.639/03 e 11.645/08), além de despertar nos educandos uma visão reflexiva acerca de seu contexto regional, histórico-cultural e sustentável, resgatando o registro da memória afro-brasileira, mas contextualizada com as problemáticas da atualidade vivenciadas pelos educandos (PINTO et al, 2015, p. 43).

Como podemos observar, de acordo com os seus objetivos, o projeto está alinhando às legislações concernente à história da África e a cultura afro-brasileira (10.639/2003 e 11.645/2008), sem falar nos PCN's, além de efetivar uma práxis pedagógica que seria fundamentada na futura Diretrizes Curriculares Nacionais para a educação Quilombola, ainda em elaboração no período. Mas o que mais importa para esse trabalho é o seu diálogo com a comunidade, no qual a escola está localizada, e a percepção desse projeto para a mesma, que a julgar pelas informações colhidas em relatos e documentação, deixou marcas profundas, ao ponto de fazer da escola uma referência para a comunidade, e não o contrário.

Entre as ações do projeto que mais chamou a nossa atenção podemos citar: a elaboração de um periódico chamado "Cipó Cultural" e a culminância do projeto, com sua ação de exposição de trabalhos pedagógico-culturais para todas as comunidades envolvidas.

O "Jornal Cipó Cultural", que apresenta muitas informações interessantes, infelizmente só tivemos acesso aos exemplares da primeira edição, ano de 2007, ano de início do projeto e a quarta edição, ano de 2010, com o projeto já consolidado após três anos consecutivos de realização do projeto.

Nessas duas edições temos similaridades, que apontam para uma linha editorial coerente com os objetivos do projeto e com uma educação reflexiva e inovadora, como prorroga as Diretrizes curriculares Nacionais para o ensino da História, já que:

As Dinâmicas das atividades, propõe-se que o professor: valorize, inicialmente, os saberes que os alunos já possuem sobre o tema abordado, criando momentos de trocas de informações e opiniões; avalie essas informações, 
identificando quais poderiam enriquecer seus repertórios e suas reflexões; proponha novos questionamentos, informe sobre dados desconhecidos e organize pesquisas e investigações; selecione materiais de fontes de informação diferentes para que sejam estudados em sala de aula; promova visitas e pesquisas em locais ricos em informações; proponha que os estudos realizados se materializem em produtos culturais, como livros, murais, exposições, teatros, maquetes, quadros cronológicos, mapas, etc. (BRASIL, 1997a, p. 53).

Ou seja, a coleta de informações para o periódico, a seleção de assuntos e as propostas de temas, inovam no quesito de ensino aprendizagem, pois insere a comunidade como protagonista, principalmente se levarmos em consideração os assuntos apresentados pelos alunos nas duas edições analisadas (2007 e 2010), onde temos vários temas distribuídos em diversos cadernos, divididos em pequenos artigos como: um breve histórico sobre a "Consciência negra", dicas de saúde, dicas de pesca, dicas de beleza, humor, cantinho cultural e até Classificados, além de receitas de culinárias. Todos os temas têm como autoria os alunos, mas supervisionados pelos professores, aonde os mesmos são entrevistados sobre o tema educação, gestão e mensagens para a comunidade discente.

Para a análise nesta pesquisa nos detemos em algumas impressões sobre este periódico fruto do "Identidade Cultural". São eles: nas duas edições do periódico, não há qualquer menção às palavras afrodescendentes e remanescentes de quilombolas, mesmo na edição de 2010. É verdade que existe a referência à "consciência negra" e imagens de figuras negras, que ilustram o material, mas no corpo do texto nos diversos artigos do "Cipó Cultural", não lemos ou identificamos palavras-chaves que façam uma associação ao território quilombola e, só há uma menção histórica ao quilombo no texto que aborda a história de Zumbi dos Palmares, na edição de 2007, sob título: Consciência negra, o que é isso afinal? Conforme a citação a seguir:

Esta é a história de um menino, Zumbi. Ele era negro, filho de escravos, mas nasceu livre, lá no quilombo dos Palmares. $\mathrm{Na}$ serra da Barriga em Pernambuco. Quilombo eram lugares dentro das matas para onde os negros fugiam, para refugiar 
do cativeiro e dos maus tratos das senzalas. Existiam muitos no Brasil e lá os escravos viviam livres em comunidades, onde faziam vales suas próprias regras. [...]. Por isso, dia 20 de novembro é dia de liberdade para os corações de todos os brasileiros (JORNAL CIPÓ CULTURAL, 2007, p. 4).

Neste caso, um texto menos reflexivo e contextualizado e mais informativo e estático, que aborda o quilombo do Zumbi dos Palmares de forma muito superficial e pouco associativo à luta comunitária da comunidade pelo reconhecimento e posse do território.

Sobre Zumbi dos Palmares nos reportamos a França e Ferreira (2012), quando analisa em seu texto "Três vezes Zumbi", o caráter de utilização do personagem Zumbi de acordo com vários períodos históricos ao se debruçarem em várias produções historiográficas, onde identificam particularidade na construção desse herói negro, que ainda se encontra no centro de disputas ideológicas e políticas.

Segundo França e Ferreira (2012), ao longo dos séculos XVI e XVII, este quilombo despertou grande interesse e "mereceu atenção de muitos letrados do período, holandeses e portugueses" (FRANÇA; FERREIRA, 2012, p. 149), com destaque para os eventos de desestabilização da autoridade colonial e metropolitana, dada as sucessivas vitórias do quilombo.

Já no século XIX, surge uma linha na historiografia que aborda Palmares como um entrave ao desenvolvimento do progresso civilizatório, tanto que a sua importância na historiografia estar em destacar os feitos de seus agressores como o paulista Domingos Jorge Velho.

E, por último apresentam uma linha de Palmares revolucionária e contestatória, onde "Zumbi é consagrado aí como o líder revolucionário por excelência" (FRANÇA; FERREIRA, 2012, p. 151). Onde aparece contextualizado com as lutas das minorias em uma sociedade com sérios problemas de ordem socioeconômicas e étnicas.

Ao nosso ver, o Zumbi apresentado e reproduzido pelos professores e alunos no "Cipó Cultural", é um Zumbi estático, herói de palmares e líder de uma revolta, bem característicos ao "primeiro Zumbi", ainda dos séculos XVI e XVII, segundo França e Ferreira (2012), pouco inserido em uma 
contextualização de uma luta comunitária pela posse do território, ou referência para a construção de uma reivindicação legítima dos afrodescendentes, pelo contrário.

A história de Zumbi aparece apenas para ilustrar o "20 de novembro", se perdendo uma grande oportunidade de conciliar, contextualizar e ressignificar os elementos de uma grande história para o povo negro e remanescentes de quilombolas que anseiam pela regularização e demarcação de seu território, como a comunidade de São José do Matapi do Porto do Céu, local onde a escola estava inserida e coletou informações para compor o seu periódico. Ou seja, nesse caso faltou uma melhor orientação aos alunos, o que sugere uma possível falha na formação continuada dos profissionais da educação, gerando um desconhecimento com as finalidades do projeto, pelo menos em tese.

Acreditamos que houve um avanço em apresentar elementos genuinamente da comunidade, onde os saberes coletivos construídos historicamente, foram levados em consideração para compor as importantes dicas em diversos aspectos, principalmente de saúde e na pesca, como podemos observar na coluna "Para uma boa pescaria", onde informa: "Se você está pensando em pescar aproveite o verão, pois é o melhor tempo para pegar peixe.

Sobre os saberes construídos historicamente pela comunidade e reconhecidos pela escola nesse projeto, os alunos recorrem às memorias dos comunitários para compor essas dicas, que são inerentes aos saberes empíricos de uma vivencia prática, essenciais ao meio sócio histórico da comunidade, o que corrobora com Selva Guimarães Fonseca quando aborda o currículo real e afirma que este: "é construído tendo por base uma série de processos e significados que envolve a cultura escolar e a cultura da vida cotidiana" (FONSECA, 2003, p. 33).

Assim, a escola construiu, na prática, elementos de um currículo real garantindo uma contextualização dos saberes adquiridos, para além de um currículo fictício e ideal, alheia à comunidade e sua especificidade histórica e cultural. Além de estar adequado aos PCN's de história já que promoveu visitas e pesquisas em locais ricos em informações além de 
propor que os estudos realizados se materializem em produtos culturais, como livros, murais, exposições, teatros, maquetes, quadros cronológicos, mapas, etc. neste caso, o "Jornal Cipó Cultural".

\section{Considerações finais}

Este trabalho que teve como objeto de análise um projeto pedagógico chamado "Identidade Cultural", que chegou a sua ga edição, na escola Estadual David Miranda, localizada na comunidade Porto do Céu, nos apresentou uma interessante experiência de ação pedagógica, onde saberes dos comunitários em conjunto com uma sensibilidade dos educadores, produziu um diálogo entre o passado e o presente que contribuiu para fortalecer a identidade local que anseia pelos seus direitos e busca resguardar a sua propriedade, construindo no cotidiano a tradição de sua luta.

Deste modo, temos que nos reportar ao conceito de identidade na "pós-modernidade", onde Stuart Hall afirma:

Em vez de falar de identidade como uma coisa acabada,
deveríamos falar de identificação, e vê-la como um processo
em andamento. A identidade surge não tanto pela plenitude
da identidade que já está dentro de nós como indivíduo, mas
como uma falta de inteireza que é preenchida a partir de
nosso exterior, pelas formas através do quais nos
imaginamos ser vistos por outros (HALL, 1997, p. 39 ).

A concepção de identidades abordada por Hall (1997), às quais relacionam-se aos contextos sociais e históricos das sociedades onde os indivíduos estão inseridos, e a formação dessa identidade passa a ser descrita de acordo com o seu papel enquanto sujeito. Nos três tipos de identidades, trabalhados por Hall (1997), é no sujeito pós-moderno que a identidade deixa de ser vista como unificada e estável, assumindo identidades diferentes em diferentes momentos. Assim, presenciamos as transformações de conceito de estrutura das instituições, bem como dos sujeitos que nela atuam, que neste caso se insere a escola e os profissionais que nela trabalham. 
Por fim, o processo de ensino aprendizagem, enquanto meio de mediação/ apropriação de conhecimento oficial, através da escola, a partir de um direito universal, como argumento Fonseca (2009), passa por diversas transformações e disputas na atualidade, sobre os conhecimentos e saberes válidos a serem ensinado ao conjunto da população, e por isso, a escola e o currículo passam por um constante e intenso processo de legitimação e disputa ideológica, o que corrobora para uma ruptura através de uma dinâmica própria, possibilitada pelos novos tempos e maior inserção de grupos subalternos no espaço escolar e, neste caso específico, entendemos que a escola que está inserida em um território periférico: um território remanescentes de quilombolas, e houve um processo de diálogo entre os atores sociais através do "Identidade cultural".

Por outro lado, o ensino de história passou por muitas transformações nos últimos anos no Brasil e no mundo, impulsionado não só pelo avanço da ciência história, mas também por uma necessidade de adequação aos novos dilemas de uma sociedade mais conectada, diversificada e acessível às novas possiblidades de reconhecimento de direitos, além da sua universalização, que exigiu um novo escopo de práticas e de linguagem para diferentes realidades (FONSECA, 2003).

Deste modo, acreditamos que a identidade e a memória dessas comunidades quilombolas serão preservadas e inseridas no contexto histórico contemporâneo como elementos valorativos de uma história, não só de luta pela sobrevivência, mas também de uma vivencia plena de conquistas, preservação e orgulho de sua cultura, construída historicamente no processo.

E, portanto, a sua identidade, saberes e jeitos de viver e ser, dos homens e mulheres dos diversos grupos étnicos brasileiros faz, ou deveriam fazer parte do processo de ensino aprendizagem, reconhecidos como conhecimentos validos para a aprendizagem e por isso, ser valorizados nos contextos das instituições de ensino.

Diante desse contexto, acreditamos que esta experiência ocorrida na escola David Miranda dos Santos, na comunidade de remanescentes de quilombola São José do Matapi, demonstra que ainda há um longo caminho 
a ser trilhado na busca de uma educação quilombola efetiva no estado do Amapá, mas os agentes sociais que fazem a escola estão se esforçando na árdua tarefa de construir uma educação adequada aos novos anseios da comunidade local como é o caso da prática do projeto "Identidade cultural".

\section{Referências}

BRASIL. [Constituição (1988)]. Constituição da República Federativa do Brasil. Brasília, DF: Senado Federal, 1988.

BRASIL. Lei n. 9.394, de 20 de dezembro de 1996. Estabelece as diretrizes e bases da educação nacional. Brasília, DF: Presidência da República, 1996.

BRASIL. Lei n. 9.475, de 22 de julho de 1997. Dá nova redação ao art. 33 da Lei n० 9.394, de 20 de dezembro de 1996, que estabelece as diretrizes e bases da educação nacional. Brasília, DF: Presidência da República, 1997a.

BRASIL. Lei no 10.639, de 9 de janeiro de 2003. Altera a Lei no 9.394, de 20 de dezembro de 1996, que estabelece as diretrizes e bases da educação nacional, para incluir no currículo oficial da Rede de Ensino a obrigatoriedade da temática "História e Cultura Afro-Brasileira", e dá outras providências. Brasília, DF: Presidência da República, 2003. Disponível em: http://www.planalto.gov.br/ccivil_03/leis/2003/l10.639.htm. Acesso em: 10 jul. 2018.

BRASIL. Ministério da Educação. Orientações e ações para a educação das relações étnico-raciais. Brasília: SECADI, 2006.

BRASIL. Ministério da Educação. Conselho Nacional de Educação. Resolução n० 08, de 20 de novembro de 2012. Parecer CNE/CEB no 16 de 2012.

Define diretrizes curriculares nacionais para educação escolar quilombola na educação básica. Brasília: CNE, 2012. Disponível em:

http://www.seppir.gov.br/portal-antigo/arquivos-pdf/diretrizes-curriculares. Acesso em: 19 jan. 2018.

BRASIL. Ministério da Educação. Parâmetros Curriculares Nacionais: História. Brasília: Secretaria de Estado da Fazenda, 1997b.

CONAE - Conferência Nacional de Educação. Documento Final. 2012.

Disponível em:

http://conae.mec.gov.br/images/stories/pdf/pdf/documetos/documento_fin al_sl.pdf. Acesso em: 6 maio 2018.

CUSTÓDIO, Elivaldo Serrão. Educação escolar quilombola no estado do Amapá: das intenções ao retrato da realidade. Educação (UFSM), Santa 
Maria, p. e15-21, fev. 2019. ISSN 1984-6444. Disponível em:

https://periodicos.ufsm.br/reveducacao/article/view/30826. Acesso em: 15 jun. 2019.

FRANÇA, Jean Marcel Carvalho; FERREIRA, Alexandre Ricardo. Três vezes Zumbi: a construção de um herói brasileiro. Três estrelas: São Paulo, 2012.

FONSECA, Selva Guimarães. Didática e prática de ensino de história.

Campinas: Papirus, 2003.

FONSECA, Selva Guimarães. Didática de ensino de história: experiências reflexões e aprendizado. Papirus, Campinas, 2009.

GOMES, Flávio dos Santos. Nas fronteiras da liberdade: mocambos, fugitivos e protesto escravo na Amazônia colônial. An. Arq. Públ. Pa, Belém, 1996.

HALL, Stuart. A identidade cultural na pós-modernidade. Rio de Janeiro: DP\&A Editora, 1997.

JORNAL CIPÓ CULTURAL. Informativo das turmas 621 e 622 da Escola Estadual David Miranda. Coordenação e editoração: Terezinha Sales. $1^{a}$ ed. Santana-AP, novembro de 2007, p. 1-4.

JORNAL CIPÓ CULTURAL. Informativo produzido pela turma 821 da Escola Estadual David Miranda. Coordenação e editoração: Terezinha Sales. $4^{a}$ ed. Santana-AP, dezembro de 2010, p. 1-6.

LARA, Silvia Hunold. Campos da violência: escravos e senhores na capitania do rio de janeiro, 1750 - 1808. Rio de Janeiro: Paz e terra, 1988.

LEITE, Ilke Boaventura. Os quilombos no Brasil: questões conceituais e normativas. Etnográfica, Portugal, v. 4, n. 2, p. 333 - 354, 2000.

LUNA, Veronica Xavier. Entre o Porteau e o Volante: africanos redesenhando a Vila de São José de Macapá. João Pessoa: Editora Sal da Terra, 2011.

PINTO, Diana Chagas et al. Um relato de experiência: Escola Estadual David Miranda As manifestações étnico raciais amapaenses, 2015, p. 41-47. In: SOUZA, Silvaney Rubens; ROCHA, Elke (org.). Caderno de projetos e propostas pedagógicas para a implementação da lei 10.639/2003. Macapá: NEER/SEED, 2015.

NUNES, Georgina Helena Lima (Org.). Educação quilombola. Brasília: SECADI, 2006.

SALLES, Vicente. O negro e as transformações sociais no fim do século XIX no Grão-Pará. Brasília: Microedição do Autor, 1988. 
SALLES, Vicente. O Negro no Pará. 2. ed. Brasília: Ministério da Cultura, 1989.

SANTOS, Milton. Por uma Geografia nova: da crítica da Geografia a uma Geografia Crítica. São Paulo: Edusp, 2002.

SILVA, Petronilha Beatriz Gonçalves. Aprender, ensinar e relações étnicoraciais no Brasil étnico-raciais no Brasil. Educação, Porto Alegre, ano 30, v. 3, n. 63, p. 489-506, set./dez., 2007.

SOUZA, Silvaney Rubens; ROCHA, Elke (org.). Caderno de projetos e propostas pedagógicas para a implementação da lei 10.639/03. Macapá: NEER/SEED, 2015.

VIDEIRA, Piedade Lino. Marabaixo, dança afrodescendente: significando a identidade étnica do negro amapaense. Fortaleza: Edições UFC, 2009.

Recebido em 25 de setembro de 2018 Aprovado em 12 de junho de 2019 